\title{
A heurística do medo, muito além da precaução
}

RICARDO ABRAMOVAY I

\section{Apresentação ${ }^{1}$}

$\mathrm{M}$

EDO E CULPA são os piores adversários da mobilização social contra o aquecimento global. Esses sentimentos ampliam a distância entre a convergência científica em torno das mudanças climáticas (Cook et al., 2013) e o ceticismo a seu respeito em parcela significativa da opinião pública, sobretudo nos Estados Unidos (Leiserowitz et al., 2013). Uma das mais importantes conclusões dos estudos do comportamento humano sob o ângulo da cultura (Hoffman, 2015), da psicologia (Stoknes, 2015) e da ética (Jamieson, 2014) é que os cenários apocalípticos, tão frequentemente traçados para caracterizar a crise socioambiental contemporânea, levam os indivíduos a fechar-se sobre seus grupos sociais de referência, a insistir na legitimidade de seus modos de vida e de consumo e a rejeitar mudanças em seus hábitos e em suas crenças (World Bank, 2015). Essa é uma das razões pelas quais grandes organizações socioambientais vêm insistindo, com razão, numa agenda positiva, tentando mostrar que a vida sob uma economia de baixo carbono pode ser melhor que a dependente do consumo em larga escala de combustíveis fósseis. O esforço do Greenpeace (2015) em apresentar as renováveis modernas como alternativas às fontes convencionais e a divulgação, por parte do WWF (2012), de exemplos empresariais socioambientalmente construtivos vão nessa direção.

Se isso é verdade, por que então evocar a importância da heurística do medo, cuja principal expressão intelectual está na obra de um dos mais importantes pensadores do século XX, Hans Jonas? Por que insistir na "primazia do mau prognóstico sobre o bom", do "princípio responsabilidade" sobre o "princípio esperança", do medo sobre a utopia, como o faz Jonas? Por que razão "é necessário dar mais ouvidos à profecia da desgraça que à profecia da salvação" (Jonas, 2015, p.40)? E por que razão opor precaução a heurística do medo? A precaução - e o princípio que, em torno dela, tornou-se moeda corrente em legislações nacionais e acordos globais (Sunstein, 2003; Veiga, 2013) - não é barreira eficaz contra aquilo que provoca medo?

O que está em jogo nessas perguntas são duas esferas centrais da organização social contemporânea, cuja expansão, desde o século XIX, nem de longe foi acompanhada por uma elaboração ética que as enquadrasse e delimitasse: a ciência e a tecnologia. Esta reflexão é necessária pelo fato de que 
a promessa da tecnologia moderna se converteu em ameaça. Concebida para a felicidade humana, a submissão da natureza, na sobremedida de seu sucesso, que agora se estende à própria natureza do homem, conduziu ao maior desafio já posto ao ser humano pela sua própria ação. (Jonas, 2015, p.21)

Mas não seria impróprio estabelecer uma ética (ou seja, um conjunto de regras relativas ao bem e ao justo) da ciência e da técnica? Por que não definir a ética da ciência com base simplesmente em procedimentos que permitam a busca honesta do conhecimento, deixando que suas aplicações práticas possam, em sua diversidade, responder à expectativa de que beneficiem a vida social? Que a organização social suponha bases éticas, disso não há dúvida. Mas por que razão o conhecimento e a criatividade teriam que renunciar àquilo que a curiosidade e o interesse determinam para submeter-se a preceitos de natureza ética? A heurística do medo não se traduziria em paralisia das inovações científicas e tecnológicas das quais dependem, fundamentalmente, as alternativas aos problemas socioambientais contemporâneos?

Este artigo procura mostrar, à luz da obra de Hans Jonas, que a heurística do medo nunca foi tão atual, nem tão urgente o imperativo de uma ética da civilização tecnológica. A leitura de Jonas aqui proposta é próxima à de Jean-Pierre Dupuy (2002) e totalmente coerente com sua proposta de um "catastrofismo esclarecido", sua crítica ao princípio da precaução e a importância que ele atribui à metafísica em que se baseia o princípio responsabilidade.

É bem verdade que o desenvolvimento científico e tecnológico abre caminho, hoje, a possibilidades muito mais promissoras de enfrentar os problemas socioambientais contemporâneos do que durante a vida de Jonas. Que se trate de energias renováveis modernas (Barnham, 2014; Jacobson; Delucci, 2009), de novas formas de conceber a organização urbana (Girardet, 2015) ou do horizonte de uma economia capaz de usar cada vez menos recursos materiais, energéticos e bióticos (McDonough; Braungart, 2013), ciência e tecnologia são as bases desses avanços. O importante, no entanto, é que, em cada um desses exemplos, o desenvolvimento científico e tecnológico está organicamente vinculado a uma formulação ética cuja base é uma relação entre sociedade e natureza que rompe com aquilo que marca a filosofia e a cultura da Idade Moderna. Ao mesmo tempo, como será visto ao final deste trabalho, nunca foi tão ameaçadora como agora a empáfia com que, na biologia e na geoengenharia, ciência e técnica se propõem a enfrentar os grandes problemas atuais. O Princípio Responsabilidade não preconiza, ao contrário do princípio da precaução, que se reduzam as incertezas no conhecimento como condição para validar a tentativa de interferir na dinâmica do sistema climático por meio de aerossóis lançados à atmosfera ou da mudança na composição química dos oceanos, para combater a mudança climática. Nessa e em tantas outras intervenções humanas derivadas da ciência e da tecnologia, o que está em jogo não é a incerteza (que está na base do princípio da precaução), mas as bases éticas da tomada de decisão. 


\section{O dualismo como traço central da Idade Moderna}

O primeiro capítulo do Princípio Responsabilidade tem início com uma "angustiosa homenagem ao opressivo poder humano" representado no canto coral da Antígona de Sófocles. Aí, Sófocles exalta as maravilhas da Natureza, das quais "a maior é o homem", cuja inteligência lhe permite fazer tanto o bem como o mal. Violar a natureza, mas, ao mesmo tempo, construir sua morada (a civilização) são as duas faces de seu poder. Mas por maior que seja esse poder, ele é pequeno diante da grandeza do mundo natural. Essa força e essa grandeza nem de longe são atingidas pelo engenho humano. Essa é a mensagem básica que Jonas extrai do canto de Sófocles.

Há, no entanto, uma diferença crucial entre a expressão desse poder entre os gregos e, em geral, em todas as sociedades que precedem a Revolução Científica do século XVII e o que ocorre a partir de então. Nunca o conhecimento e sua aplicação prática se haviam convertido (para empregar o termo que Karl Polanyi reservou à economia) em esferas autônomas da vida social. Por mais que as técnicas modificassem a vida humana (a agricultura e o surgimento das cidades são expressões emblemáticas desta modificação), não se pode dizer que elas fossem "conscientemente criadas" (Jonas, 2015, p.34) para essa finalidade: ninguém inventou a agricultura ou as cidades. Elas emergiram e o próprio termo revolução, nesse sentido, escamoteia esse sentido de lenta emergência. Mais que isso, o progresso obstinado e cumulativo do conhecimento tampouco faz parte dos comportamentos sociais anteriores à Revolução Científica do século XVII. A partir de então, "o poder [da ciência e da técnica] tornou-se autônomo, enquanto sua promessa transformou-se em ameaça e sua perspectiva de salvação, em apocalipse" (ibidem, p.237). O poder humano foi muito além da capacidade de prever suas consequências, mostra Morris (2013), em sua análise da obra de Jonas.

O conhecimento sobre o mundo e as técnicas que daí resultam integravam-se, antes da Revolução Científica, organicamente à vida social. Jonas certamente subestima a força destrutiva de algumas sociedades tradicionais. ${ }^{2}$ Mas ele está correto ao afirmar que jamais essa força destrutiva adquiriu alcance global, crescimento incessante e muito menos interferiu, como o faz agora por meio da manipulação genética, na própria natureza humana, tema de sua outra grande obra, o Princípio Vida (Jonas, 2004). Essas características, sob o ângulo cultural e filosófico, exprimem o que Jonas $(2015$, p.235) chama de "programa baconiano", que consiste em "colocar o saber a serviço da dominação da natureza e utilizá-la para melhor sorte da humanidade". Além disso, Jonas chama a atenção para uma dimensão temporal da intervenção humana sobre a natureza que envolve não só os impactos de longo prazo da emissão de gases de efeito estufa, mas dinâmicas ecossistêmicas desencadeadas pela ação social sobre as quais a noção tradicional de responsabilidade não se aplica. É neste sentido que Jonas $(2015$, p.40) diz: "toda ética tradicional contava somente com um comporta- 
mento não cumulativo". As cadeias causais entre uma ação e suas consequências se alongam e, de forma cada vez mais frequentes, não são passíveis de previsão. Consequentemente, "a velocidade do desenvolvimento alimentado por tecnologia não deixa tempo para autocorreção" (Jonas apud Morris, posição 3060). A consequência é que as correções vão se tornando cada vez mais difíceis e menor a liberdade para levá-las adiante, como bem o mostra o exemplo das mudanças climáticas.

A Revolução Científica do século XVII transforma a natureza em objeto de conhecimento, em passividade sobre a qual será exercida a atividade cognitiva e transformadora humana. A natureza se torna exterior à consciência. Corpo e alma, matéria e espírito, sociedade e natureza são as formas mais notáveis do dualismo que se torna traço dominante da cultura moderna. É nessa condição de forma objetiva, desprovida de qualquer dimensão espiritual própria que o destino da natureza consiste em submeter-se inteiramente aos propósitos humanos. Muito mais que um tema de natureza epistemológica, uma forma de conhecer e de se apropriar do mundo, o que está em jogo a partir da Revolução Científica é uma cultura, cuja base filosófica reside na completa separação entre "ser e dever, causa e finalidade, natureza e valor" (Jonas, 2015, p.22).

Numa conferência pouco antes de sua morte, Jonas fala desse "dualismo metafísico que polarizou o pensamento ocidental desde suas origens, no platonismo e no cristianismo" (Jonas, 1994, p.821). "Alma e corpo, mente e matéria, a vida interior e o mundo externo eram, senão hostis, ao menos alheios um ao outro e poderiam juntar-se teoricamente só com muita dificuldade" (ibidem).

A cisão entre ciências e humanidades é a mais emblemática expressão dessa fratura. ${ }^{3}$ É o que separa ética e conhecimento objetivo (dando lugar ao surgimento da ciência, que se ocupa exclusivamente do ser, das causas e não do dever, do significado e dos valores) e afasta a necessidade de introduzir valores nas relações entre homens e mundo natural. Na filosofia moderna, valores são restritos às relações entre pessoas. O preceito kantiano ("Age apenas de acordo com uma máxima que possas, ao mesmo tempo, querer que se torne uma lei universal") é estritamente intersubjetivo e adequado a uma época histórica em que o poder humano sobre a natureza era limitado e, mesmo quando destrutivo, limitado a situações locais.

É por isso que a civilização tecnológica exige uma nova ética em que a natureza seja tratada não como objeto pronto a receber a intervenção social, mas como sujeito da condição básica da existência social, isto é, da própria vida. A humanidade tornou-se uma espécie de "fiel depositário" (Jonas, 2015, p.41) da vida e, por isso, sua preservação precisa ser incorporada ao conceito de bem humano. A visão científica da natureza não preparou a sociedade a desempenhar esse papel e muito menos suas aplicações tecnológicas.

Sob o ângulo da ciência, a natureza está despida de "toda dignidade de fins" (ibidem, p,42). A abordagem de Jonas inspira-se claramente em seu pro- 
fessor Edmund Husserl (1970), para quem embora a ciência esteja ampliando incessantemente sua capacidade de conhecer o mundo, ela é incapaz de refletir sobre o que ela própria significou e pode significar para a existência humana. A ciência exclui de seu âmbito próprio questões referentes ao significado ou à falta de significado de toda a existência humana.

A filosofia de Jonas é explicitamente antipositivista. Ela se aproxima da posição de Max Weber em "Ciência como vocação" quando sustenta que "as ciências naturais não pronunciam toda a verdade sobre a natureza". Em O Princípio Vida, ele mostra que as regras da biologia científica a "mantêm presa aos fatos físicos exteriores" e forçam-na a "ignorar a dimensão da interioridade, que faz parte integrante da vida... O sentido da vida, quando explicado unicamente através da matéria, torna-se mais enigmático do que antes" (Jonas, 2004, p.7).

É com base nessas premissas que Jonas $(2005$, p.47) reelabora o preceito kantiano, nos seguintes termos: "age de modo que os efeitos da tua ação sejam compatíveis com a permanência de uma autêntica vida humana sobre a Terra". Esse preceito contesta o dualismo metafísico em que se apoia a filosofia e, mais que isso, a cultura Ocidental. O ser da natureza não se afasta do dever ético de sua preservação. A rede de nexos causais capazes de explicar sua evolução não se separa de uma finalidade, que não se confunde e não se pode confundir com sua explicação científica: essa finalidade é a própria vida. E com isso, a natureza deixa de ser apenas um conjunto objetivo de fatos e circunstâncias, mas torna-se um valor capaz de propiciar sentido, significado à própria ação humana.

Como ele mostra na conferência ao final de sua vida, as polaridades que marcam a história da filosofia (corpo e alma, ser e dever, causa e finalidade, natureza e valor) ganham uma dimensão prática decisiva em virtude da própria autonomia do crescimento do conhecimento científico e dos riscos crescentes de suas aplicações tecnológicas. Nós, os criadores não intencionais desses riscos, temos agora o dever de evitá-los: "a reconciliação entre nosso presunçoso status especial como humanos e o universo como um todo, que é a fonte de nossa vida, torna-se uma questão central da filosofia" (Jonas, 1994, p.14).

A reformulação do preceito kantiano muito além de sua dimensão originalmente intersubjetiva conduz a dois desafios centrais. O primeiro consiste em romper com o dualismo que marca a história da filosofia ocidental. Essa ruptura passa pelo reconhecimento de que nós, a inteligência humana, a alma, a mente, o único lado supostamente ativo da polaridade acima mencionada, somos produtos da própria evolução, resultamos da "mesma substância presente nas galáxias e nos planetas e que permitiram o surgimento do prazer, da dor, do desejo, do medo, do sentir e do olhar, do amor e do ódio" (ibidem, p.827). O dualismo era admissível enquanto essas capacidades humanas não ameaçavam o conjunto da vida. "A reconciliação entre nosso presunçoso status especial como seres humanos e o universo como um todo, que é a fonte de nossa vida, está se tornando um tema central da filosofia." 
O segundo é um dever de humildade e de prudência que deve guiar o conhecimento e sua aplicação tecnológica e que explica a aversão de Jonas à "escatologia secularizada" (Jonas, 2015, p.287), marca das mais importantes utopias redentoras do século XX. Essa aversão não se refere apenas ao mito de que uma nova racionalidade econômica pode ser suficiente para romper com os efeitos do dualismo denunciado por Jonas. O dever de humildade refere-se, como bem mostra Jean-Pierre Dupuy (2002), ao reconhecimento de que não é possível dispor dos instrumentos cognitivos capazes de prever os impactos catastróficos de parte crescente do desenvolvimento científico e tecnológico contemporâneo. É o que será visto a seguir.

\section{A ilusão e os perigos da utopia}

A reconciliação preconizada por Jonas não virá por meio de uma organização social superior. Hans Jonas é um crítico do capitalismo e de sua premissa mais importante, o crescimento econômico. Ele denuncia a "irracionalidade de uma economia dominada pela busca do lucro" e admite que

o socialismo pode contrapor a promessa de maior racionalidade na administração da herança baconiana. O planejamento centralizado de acordo com as necessidades coletivas pode evitar os grandes desperdícios da lógica da competição, bem como os disparates de uma produção de mercado que visa a seduzir o consumidor. (Jonas, 2015, p.242)

Ao mesmo tempo, entretanto (e seu livro é publicado dez anos antes da queda do Muro de Berlim), a experiência real mostra que a parcimônia no comportamento dos consumidores na economia centralmente planificada é resultado muito mais da ineficiência, da burocracia e da pobreza, do que de algum tipo de virtude ética socialmente reconhecida e relativa à maneira de satisfazer as necessidades sociais. Claro, diz ele, "que o critério das necessidades constitui uma premissa melhor para a racionalidade... do que o critério do lucro" (ibidem). Mas nada indica que uma economia centralmente planificada seja capaz de aplicar esse critério.

Mais que isso, embora a economia centralmente planificada exclua o lucro privado, ela persegue o lucro coletivo. E isso se faz por meio de técnicas tão predatórias (na verdade, revelaram-se frequentemente mais predatórias) que as aplicadas no capitalismo. Uma das razões para isso é que numa economia centralmente planificada, os custos econômicos da destruição são ainda menos visíveis que naquela regida pelo sistema de preços.

Em ambos os casos, está em curso a aplicação do "ideal baconiano de dominação da natureza por meio da técnica" (ibidem, p.235), cujo resultado (tanto no capitalismo como no socialismo) é o "um crescimento enorme do intercâmbio metabólico entre o corpo social e o ambiente natural" (ibidem, p.235).

É antes de tudo em nome da prudência que Hans Jonas se insurge contra qualquer modalidade de grande utopia. Jean-Pierre Dupuy (2002, p.159-60) resume bem a tensão a que essa prudência conduz e, ao mesmo tempo, as conse- 
quências práticas da metafísica em que se apoia Jonas. A passividade da natureza, sua permanente prontidão a ser descoberta e dominada pela razão é reflexo de um mundo em que os fenômenos naturais podem ser (ao menos é o que se acredita) não só conhecidos, mas até previstos. $\mathrm{O}$ traço constitutivo da civilização tecnológica está no "excesso de nossa potência sobre nossa capacidade de prever as consequências de nossos atos". Isso nos impõe, ao mesmo tempo, "a obrigação moral de prever o futuro e nos torna incapazes de fazê-lo".

Imaginar que essa radical incerteza pode ser superada por alguma técnica estatística de cálculo de risco é ilusório e aí se concentra a crítica de Jean-Pierre Dupuy ao Princípio da Precaução. A abordagem de Hans Jonas não se refere a uma dimensão tópica e localizada do progresso técnico, mas à mudança no caráter e na capacidade geral da intervenção humana sobre os ecossistemas, na incerteza crescente a que essa intervenção conduz e no horizonte catastrófico a que ela dá lugar. Por mais útil que seja o exercício de calcular a dimensão dos impactos da tecnologia, a incerteza inspirada na heurística do medo refere-se aos modos de vida que essa tecnologia permitiu. Daí resulta não um convite à paralisia das inovações, e sim um apelo a que essas sejam permanentemente norteadas por uma orientação ética sintetizada na revisão que faz Jonas do princípio kantiano.

Só pode inspirar desconfiança um projeto que, sob o pretexto de combater a organização social baseada no lucro, mantenha intacto o programa baconiano e busque intensificar o metabolismo entre sociedade e natureza, mesmo que visando necessidades sociais e não mais o lucro. A heurística do medo preconiza o reconhecimento permanente da ignorância como o outro lado do saber, e nesse sentido é um antídoto contra a ambição de uma organização social cujos princípios de justiça afastassem a necessidade de uma ética da ciência e da tecnologia.

\section{Duas aplicações contemporâneas: biologia e geoengenharia}

A biologia e a geoengenharia representam hoje, talvez, os exemplos mais emblemáticos da atualidade da heurística do medo. No que se refere à biologia, o alerta fundamental vem de Edward Wilson. "Nós criamos uma civilização de guerra das estrelas, com emoções da Idade da Pedra, instituições medievais e tecnologias divinas (Wilson, 2012, posição 147). Em sua obra mais recente Wilson (2014, posição 67) constata que

nossa espécie começou a cruzar o limiar mais importante, embora menos examinado da era tecnocientífica. Estamos na iminência de abandonar a seleção natural, o processo que nos criou, dirigindo nossa própria evolução por vontade seletiva - o processo de redesenho da nossa natureza humana e biológica como nós gostaríamos que ela fosse.

Em nenhum momento Wilson sugere que se interrompa a pesquisa em torno desses temas. Mas é claro que essa forma extrema de controle da natureza, por ele mencionada, não pode ser apenas saudada como sinal de progresso. E é exatamente por isso que Edward Wilson tornou-se um dos mais ardorosos 
defensores da valorização das humanidades, tanto quando do próprio conhecimento científico. Seu mais recente livro chega a defender a "possibilidade de unificação destes dois grandes ramos da aprendizagem" (Wilson, 2014, posição 44 ), as humanidades e as ciências. Vale a pena mencionar duas dimensões centrais dessa defesa.

A primeira encontra-se na bela carta que em 2008 Edward Wilson dirige a um pastor propondo uma aliança para salvar a Criação, ou seja, a vida na Terra. O ponto de partida é o reconhecimento de que as explicações sobre a criação vindas da ciência e da religião são opostas e irreconciliáveis. "Deus fez a criação, é o que o senhor diz", escreve Wilson (2008). Já a ciência sustenta a ideia de que "a vida se fez a si mesma, por meio de mutações aleatórias e da seleção natural das moléculas codificadoras”. Mas, apesar desse antagonismo, a ciência sozinha é incapaz de enfrentar os grandes problemas socioambientais contemporâneos e é urgente que os valores éticos embutidos na religião (defesa da criação e respeito pela vida) contribuam também para esse enfrentamento. Uma das justificativas para essa proposta (e aqui Wilson exprime uma crítica ao cientificismo que faz eco às preocupações de Max Weber em Ciência como voca$c ̧ \tilde{a} o)$ é que desde o Neolítico "temos procurado nos elevar saindo da natureza, em vez de ascender rumo a ela". O flerte com o sagrado contido na frase não deve escamotear alguns dos mais férteis programas de pesquisa e de intervenção tecnológica levados adiante em áreas econômicas as mais diversas entre os quais estão a biomimética, ${ }^{4}$ a economia circular (Ellen McArthur Foundation, 2015) e o trabalho organizado a partir dos livros de William McDonough e Michael Braumgart (2002 e 2013). Aprender com a natureza não consiste em lidar com uma entidade mágica e intocável, à qual se opõe uma outra que lhe é estranha e exterior, a sociedade. Ao contrário, exige muita ciência, mas também supõe um conjunto de virtudes éticas que a ciência e a tecnologia por si só jamais serão capazes de oferecer.

Daí a importância da segunda razão pela qual é fundamental valorizar as humanidades e não só o conhecimento científico e suas aplicações tecnológicas. O significado da existência humana é o título do mais recente livro de Edward Wilson. Nas humanidades, escreve Wilson (2014), significado, sentido são termos equivalentes a intenção, design e que supõem, portanto, um designer. Para as ciências, ao contrário, significado é a capacidade de estabelecer relações causais entre eventos aleatórios cuja destinação pode ser explicada pelo encadeamento empiricamente constatável a que esses eventos deram lugar, mas de forma alguma prevista em razão de um projeto ou uma intenção neles contida. "A fonte de significado são os acidentes da história e não as intenções de um designer" (Wilson, 2014, posição 51). E esses acidentes - responsáveis por gerar a inteligência humana, a capacidade de defender seus próprios interesses e sobretudo a de viver em grupo e, por aí, de criar a civilização - respondem pelo contraste entre as exigências de uma organização social complexa e as dificulda- 
des de nossa própria capacidade cognitiva e emocional para conhecer e interferir sobre essa organização. Se essas dificuldades podem ser explicadas pela evolução, seu enfrentamento exige a capacidade de imprimir significado, sentido às ações humanas com base na maneira como as humanidades, e não as ciências, definem esses termos. O livro de Wilson termina com essa lição de sabedoria:

ciência e humanidades, é verdade, são fundamentalmente diferentes uma da outra, no que fazem e dizem. Mas elas são complementares na origem e emergem do mesmo processo criativo da mente humana. Se o poder heurístico e analítico da ciência puder ser unificado à criatividade introspectiva das humanidades, a existência humana ascenderá a um significado infinitamente mais produtivo e interessante. (Wilson, 2014, posição 1984)

A segunda expressão contemporânea da heurística do medo vem da geoengenharia. Clive Hamilton (2013) mostra que "por sua pura audácia, nenhum plano elaborado por seres humanos ultrapassa o que pretende controlar o clima da Terra". O exemplo da geoengenharia é um caso, de certa forma extremo, na forma como a ciência e a tecnologia interferem na própria relação entre sociedade e natureza. A geoengenharia é uma espécie de operação limpeza, subsequente ao despejo do lixo fóssil na atmosfera e cuja base é a investigação de "métodos para manipular a cobertura de nuvens da Terra, mudar a composição química dos oceanos e cobrir o Planeta com uma camada de partículas capazes de refletir o sol".

Ela representa, nesse sentido, "mudança profunda na relação do Homo Sapiens com a Terra. No século XXI, o destino da natureza passou a depender da boa vontade dos humanos e à medida que os humanos são parte da natureza, o sistema Terra adquiriu força moral. Portanto a geoengenharia não é um problema tecnológico, nem mesmo puramente ético, tal como usualmente compreendido. Ela se refere ao que significa para uma espécie deter o futuro do Planeta em suas mãos" (Hamilton, 2013, posição 57).

O que está em jogo aqui é a exigência de precaução (e não a fé cega na capacidade da ciência e da tecnologia) que Edward Wilson também reivindica. Os bilhões de dólares até aqui recebidos pelas pesquisas em geoengenharia ${ }^{5}$ não são apenas expressões científicas da curiosidade e do engenho humano.

E para demonstrá-lo Clive Hamilton (2013, posição 2480) mostra que a geoengenharia é apresentada frequentemente como uma espécie de Plano B das mudanças climáticas, aquele que teria que ser adotado na ausência de qualquer alternativa viável. $\mathrm{O}$ interessante é que os principais responsáveis pela falência do Plano A (que consiste, claro, em reduzir drasticamente as emissões) são os protagonistas e os defensores desse Plano B. Aí estão incluídas não só organizações empresariais norte-americanas que financiaram o negacionismo climático, mas também diversas empresas fósseis. É por isso que Clive Hamilton caracteriza a geoengenharia com a expressão, amplamente utilizada na microeconomia contemporânea, moral hazard. Ou seja, é um procedimento que, longe de levar à 
redução do problema em sua origem, promete resolvê-lo, o que pode ter por consequência um agravamento dos males que ele quer corrigir. Isso porque, como a solução supostamente existe, o processo em questão deixa de ser visto como um problema. Com a geoengenharia, seria possível continuar emitindo gases de efeito estufa, já que existiriam técnicas capazes de evitar que estas emissões destruíssem o sistema climático global. É nesse sentido que Newt Gingrich, ex-candidato republicano à presidência dos Estados Unidos, afirmava em 2008: "em vez de penalizar os americanos comuns, temos a opção de tratar do aquecimento global recompensando a invenção científica", conforme relata Hamilton (2015).

Da mesma forma que Edward Wilson, Clive Hamilton (2013, posição 2921) mostra que essa crença incondicional nas virtudes das aplicações tecnológicas da ciência reflete a visão da "autonomia dos humanos frente à natureza, enraizada no pensamento moderno". Ao final de seu livro, Hamilton constata o paradoxo de se buscar na habilidade tecnológica as soluções para o desejo de comandar o mundo natural: "a menos que nos perguntemos por que certo tipo de racionalidade falhou, apelos para mais razão parecem quixotescos" (Hamilton, 2013, posição 2992). E na raiz dessa racionalidade, o que ele encontra é algo essencial à "natureza dos humanos modernos - a determinação de moldar o mundo à nossa volta para satisfazer desejos que parecem não ter limite" (Hamilton, 2013, posição 2999).

\section{Conclusões}

A heurística do medo não é um convite à paralisia da pesquisa científica, nem de suas aplicações tecnológicas. "Seguir adiante nos desafios do conhecimento é um dever supremo" (Jonas, 2015, p.270). Mas esses desafios não podem ser enfrentados de forma cega. Eles exigem prudência, responsabilidade e, antes de tudo, autorreflexão e busca de sentido. Esse sentido não vem da presumida capacidade utópica de implantar uma civilização racionalmente planejada. Tal crença simplesmente escamoteia o dever de transformar o dualismo que marca a relação entre sociedade e natureza desde a Revolução Científica do século XVII. O sentido só pode vir do respeito à própria vida, da humildade diante da sua grandeza e do reconhecimento de que, apesar de sua força, o homem é o resultado da evolução e tem hoje, mais que nunca, a responsabilidade não só pelo seu próprio futuro, mas pelo futuro da própria vida. Jonas, Wilson, Hamilton e parte crescente dos cientistas e tecnólogos contemporâneos procuram nortear seus trabalhos pela preocupação explícita em reunificar aquilo que a Idade Moderna separou, sociedade e natureza.

Imaginar que uma sociedade voltada explicitamente à satisfação das necessidades humanas vai alterar por si só os potenciais destrutivos embutidos inevitavelmente no avanço da ciência e da técnica é mais que ilusório: é expressão de prepotência, é renunciar à tarefa atual mais urgente, qual seja 
o esforço consciente para assumir um medo desinteressado, no qual junto com o mal apareça o bem a ser defendido, junto com o infortúnio apareça uma salvação que não faça exigências demasiadas [e por isso] o medo se torna a primeira obrigação preliminar de uma ética da responsabilidade histórica. (Jonas, 2015 , p.352)

\section{Notas}

1 Agradeço as sugestões de José Eli da Veiga, Carlos Eduardo Lessa Brandão, Bernardo Sorj, Sérgio Esteves e Ademar Romeiro. Agradeço também as observações de Dália Maimon e John Wilkinson à minha apresentação no ciclo de debates "A Busca do Sentido Perdido", organizado por Bernardo Sorj, no Instituto de Estudos Avançados da Universidade de São Paulo, em 2014. Mesmo que motivado por aquela apresentação, este texto pouco contém de seu conteúdo inicial. Claro que as pessoas aqui mencionadas não são responsáveis pelos erros e imprecisões do presente artigo.

2 Muito embora, ele reconheça também este poder destrutivo, logo no início do primeiro capítulo do Princípio Responsabilidade: “...as interferências do homem na natureza, tal como ele próprio as via, eram essencialmente superficiais e impotentes para prejudicar um equilíbrio firmemente assentado". Mas logo em seguida ele acrescenta: "o retrospecto descobre que a verdade nem sempre foi tão inofensiva” (Jonas, 2015, p.32).

3 Como será visto ao final deste trabalho, reunificar ciências e humanidades está no centro do trabalho recente de um dos ícones da biologia contemporânea, Edward Wilson (2008, 2013, 2014).

4 Disponível em : <http://static.biomimicry.net/wp-content/uploads/2012/02/The_ Feedback_Loop.pdf>.

5 E cujos produtos práticos, além de arriscados, só teriam efeitos a partir de 2030, o que coloca em questão sua real utilidade.

\section{Referências}

BARNHAM, K. The burning answer. A user's Guide to the Solar Revolution. London: Weindenfeld \& Nicolson, 2014.

COOK J. D. et al. Quantifying the consensus on anthropogenic global warming in the scientific literature. Environmental Research Letters, v.15/5, 2013. Disponível em: <http://iopscience.iop.org/article/10.1088/1748-9326/8/2/024024;jsessionid=9 362146E5703D809C33E9D844CD40298.c2.iopscience.cld.iop.org>. Acesso em: 24 out. 2015.

DUPUY, J.-P. Pour un catastrophisme éclairé. Quand l'impossible est certain. Paris: Seuil, 2002.

GIRARDET, H. Creating regenerative cities. London: Routledge, 2015.

GREENPEACE. The Energy [R] evolution, 2015. Disponível em: <http://www.greenpeace.org/international/en/campaigns/climate-change/energyrevolution/>. Acesso em: 14 out. 2015.

HAMILTON, C. Earthmasters. The dawn of the age of climate engineering. New Haven: Yale University Press, 2013. 
HOFFMAN, A. How culture shapes the climate debate. Stanford: Stanford University Press, 2015.

HUSSERL, E. The crisis of European sciences and transcendental phenomenology. Evanston: Northwestern University Press, 1970.

JACOBSON, M. Z.; DELUCCI, M. A. A path to sustainable energy by 2030. Scientific American, p.58-65, nov. 2009. Disponível em: <http://www.nature.com/scientificamerican/journal/v301/n5/full/scientificamericanl 109-58.html>. Acesso em: 24 out. 2015.

JAMIESON, D. Reason in a dark time. Why the struggle against climate change failed and what it means for our planet. Oxford: Oxford University Press, 2014.

JONAS, H. Philosophy at the end of the century: a survey of its past and future. Social Resarch, v.61, n.4, p.813-32, 1994.

Vozes, 2004.

O Princípio Vida. Fundamentos para uma biologia filosófica. Rio de Janeiro:

O Princípio Responsabilidade. Ensaio de uma ética para a civilização tecnológica. Rio de Janeiro: Contraponto; Ed. PUC-Rio, 2015.

LEISEROWITZ, A. et al. Climate change in the American mind: Americans' global warming beliefs and atitudes. Yale University and George Mason University. New Haven, CT: Yale Project on Climate Change Communication, 2013. Disponível em: <http://environment.yale.edu/climate-communication/files/Climate-Beliefs-November-2013.pdf>. Acesso em: 24 out. 2015.

McDONOUGH, W.; BRAUNGART, M. The upcycle. Beyond sustainability. Designing for abundance. New York: North Point Press, 2013.

MORRIS, T. Hans Jonas Ethic's of Responsibility. From Ontology to Ecology. New York: Suny Press, 2013.

STOKNES, P. E. What we think about when we try not to think about global warming. Toward a New Psychology of Climate Action. Vermont: Chelsea Green Publishing, 2015.

SUNSTEIN, C. R. Beyond the Precautionary Principle. University of Pennsylvania Law Review, v.151, p.1003-58, 2003.

VEIGA, J. E. A desgovernança mundial da sustentabilidade. São Paulo: Ed. 34, 2013.

WILSON, E. O. A criação. Como salvar a vida na terra. São Paulo: Cia. das Letras, 2008.

. The social conquest of the earth. New York: Liveright, 2012.

. The meaning of human existence. New York: Liveright, 2014.

WORLD BANK. World Development Report, 2015. Mind, Society, and Behavior. Washington D.C. 2015. Disponível em: <http://www.worldbank.org/content/dam/ Worldbank/Publications/WDR/WDR\%202015/WDR-2015-Full-Report.pdf>. Acesso em: 24 out. 2015.

WWF. Greengame-changers. Insights for Mainstreaming Business Innovation, 2012. Disponível em: <.http://assets.wwf.org.uk/downloads/1121_1_wwf_greengamechange_aw_web_2_.pdf>. Acesso em: 24 out. 2015. 
RESUMO - Por mais que o avanço da ciência e da tecnologia esteja na raiz de vitórias decisivas na luta por melhores condições sociais, é impossível não reconhecer a ameaça crescente que o conhecimento e suas aplicações práticas representam não só para as sociedades humanas, mas para a vida em seu conjunto. A capacidade humana de intervir sobre a natureza é hoje muito maior que a possibilidade de prever com um mínimo de segurança os resultados dessa intervenção. Para Hans Jonas esse contraste só pode ser abordado com base numa exigência ética que ele sintetiza no Princípio Responsabilidade, e que se apoia na heurística do medo. Baseado numa abordagem crítica do dualismo que marca a cultura ocidental e separa matéria e espírito, corpo e mente, natureza e sociedade, Hans Jonas rejeita a ideia de que uma organização social voltada explicitamente à satisfação das necessidades humanas (e não ao lucro) suprima a exigência de uma reflexão específica sobre as ameaças vindas da expansão autônoma da ciência e da tecnologia. Este trabalho, além de expor as bases do dualismo estudado por Jonas, procura mostrar que suas preocupações não são contempladas pela eventual adoção do princípio da precaução e mostra, ao final, duas áreas (biologia e geoengenharia) em que a aplicação de sua filosofia da tecnologia pode ser especialmente relevante.

PALAVRAS-CHAVE: Princípio responsabilidade, Princípio da precaução, Ciência \& tecnologia, Risco, Incerteza, Dualismo.

ABSTRACT - As much as the advance of science and technology lies at the root of decisive victories in the pursuit of better social conditions, it is impossible not to recognize the growing threat that knowledge and its practical applications represent not only to human societies, but also to life as a whole. Today, our capacity to intervene in nature is much greater than our ability of making minimally reliable predictions of the results of such intervention. For Hans Jonas, this contrast can only be addressed on the basis of ethical demand that he synthesizes in the Imperative of Responsibility, grounded on the heuristics of fear. Resorting to a critical approach to the dualism that characterizes Western culture and separates matter and spirit, body and mind, nature and society, Jonas rejects the idea that a social organization focused explicitly on the satisfaction of human needs (not on profit) abrogates the need to reflect specifically on the threats stemming from the autonomous expansion of science and technology. This work, in addition to exposing the foundations of the dualism studied by Jonas, seeks to show that his concerns are not addressed by an eventual adoption of the precautionary principle, and portrays in the end two areas (biology and geoengineering) where the application of his philosophy of technology can be particularly relevant.

KEYWORDS: ve of Responsibility, Precautionary principle, Science and Technology, Risk, Uncertainty, Dualism.

Ricardo Abramovay é professor sênior do Instituto de Energia e Ambiente da USP. @ - abramov@usp.br

Recebido em 4.11.2015 e aceito em 18.12.2015.

I Instituto de Energia e Ambiente, Universidade de São Paulo. São Paulo/São Paulo, Brasil. 
